\title{
Chromosome pairing in Lolium perenne $\times$ L. temulentum diploid hybrids: genetic and cytogenetic evaluation
}

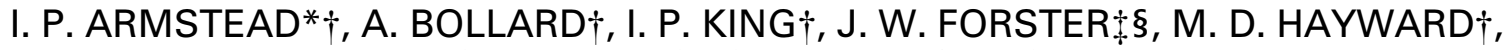 \\ G. M. EVANS $\&$ H. M. THOMAS† \\ $\dagger$ Institute of Grassland and Environmental Research, Plas Gogerddan, Aberystwyth, Ceredigion, SY23 3EB, U.K. \\ and $\$$ Institute of Biological Sciences, University of Wales, Aberystwyth, Ceredigion, U.K.
}

\begin{abstract}
A Lolium perenne genotype (E5/2/5/10), which had been selected for low chiasma frequency over a number of generations and which was suspected of containing one or two heterozygous dominant genes with a significant effect on chiasma frequency, was crossed with L. temulentum (Ba3081) to create a hybrid population of 47 diploid plants. The mean chiasma or paired arm (PA) frequency of homoeologous chromosomes at meiosis in the population was $9.1 /$ cell (1.3 PA/chromosome pair) with a distribution skewed towards high PA frequency. More than $90 \%$ of the hybrid chromosomes paired at meiosis in spite of the disparity in chromosome length and DNA quantity between the two species. Overall, the distribution of PAs between chromosomes for a given number of PAs/cell favoured the production of rod bivalents over ring bivalents and univalents, indicating that there is a mechanism present that maximizes the total number of bivalent associations formed. Molecular marker analysis using AFLPs and isoenzymes did not identify any clear major gene effect on PA frequency in the hybrid population. It was concluded that the control of PA frequency in E5/2/5/10 was not a simple genetic mechanism.
\end{abstract}

Keywords: chiasma-frequency, cytogenetics, genetics, Lolium.

\section{Introduction}

Grasses from the Lolium/Festuca complex form the major component of animal production systems in the U.K., northern Europe and the higher rainfall areas of Australia and New Zealand. The continued success of grassland agriculture in these areas depends on supporting forage grass breeding programmes that are able to generate improved varieties that respond to both climatic changes and market needs by the manipulation of recombination of the genomes of these grasses. In this context, a number of studies have taken place over the last two decades looking at the pairing behaviour of chromosomes in both diploid and polyploid interspecific hybrids. Taylor \& Evans (1977) identified genotypes of both Lolium perenne (perennial ryegrass) and L. temulentum (darnel) which contained genes that affected chiasma frequency in diploid interspecific hybrids ('high-' and 'low-pairing' genotypes) both in

*Correspondence. E-mail: ian.armstead@bbsrc.ac.uk

§resent address: Plant Sciences and Biotechnology, Agriculture Victoria, La Trobe University, Bundoora, Victoria 3083, Australia. the presence and the absence of $\mathrm{B}$ chromosomes. These genes were also shown to be active in tetraploid $L$. perenne $\times$ L. temulentum hybrids (Evans \& Davies, 1985). Further studies in L. multiflorum (Italian ryegrass) indicated a similar underlying genetic mechanism, which was also shown to be effective both in diploid interspecific hybrids (Evans \& Taing Aung, 1985) and in 'diploidizing' meiosis in tetraploid interspecific hybrids between L. perenne and L. multiflorum (Taing Aung \& Evans, 1985). Taing Aung \& Evans (1987) proposed that the genetic effect on chiasma frequency derived from $L$. perenne and observed in L. perenne $\times L$. temulentum diploid hybrids was likely to be the result of more than one gene, but a single gene (present in the heterozygous state in the 'low-pairing' parent) with a significant effect appeared to be present and linked to an isoenzyme locus.

Recently, the development of genetic mapping tools such as RFLPs and AFLPs, combined with the ability to distinguish the genomes of Lolium and Festuca spp. in interspecific hybrids using genomic in situ hybridization (Thomas et al., 1994; Humphreys \& Pasakinskiene, 1996) has enabled researchers to look at the process of 
recombination with a far higher degree of resolution. As a consequence, there has been renewed interest in exploiting the 'high- and low-pairing' genotypes originally identified by Taylor \& Evans (1977) and a 'lowpairing' $L$. perenne genotype, E5/2/5/10, derived from that identified by Taing Aung \& Evans (1987), is currently being used in a Lolium/Festuca introgression breeding population. This paper represents a further evaluation of the genetics and cytogenetics of pairing control in the E5/2/5/10 genotype.

\section{Materials and methods}

\section{Plant material}

The L. perenne genotype used, designated E5/2/5/10, was derived as follows. A single genotype (containing one B chromosome) from a cross between an Algerian accession of L perenne (Welsh Plant Breeding Station (now IGER), Aberystwyth (UK) and the L. perenne variety S23 was open-pollinated with the $L$. perenne variety S24. The progeny from this cross were scored for chiasma frequency and a 'low-pairing' genotype (Lp19 - the progeny of which showed reduced chiasma frequency both in the presence and absence of the B chromosome) was selected. Lp19 was backcrossed four times to the $L$. perenne variety Aurora, with single genotype selection for low chiasma frequency at each generation. In the genotype produced from the final selection $(\mathrm{E} 5 / 2 / 5 / 10)$ the $\mathrm{B}$ chromosome had been eliminated. The $L$. temulentum genotype used in the testcross was Ba3081 (Welsh Plant Breeding Station), a naturally inbreeding annual maintained by selfing for over 20 years since its acquisition. This genotype has previously been identified as being suitable for the establishment of $L$. perenne $\times$ L. temulentum hybrids and for cytological analysis (Taylor \& Evans, 1977; Taing Aung \& Evans, 1987; Scanlon, 1988; Wolstenholme, 1993).

\section{Testcross}

Emasculated inflorescences of Ba3081 were hand-pollinated with pollen from E5/2/5/10. Hybrid embryos were rescued at about 20 days and established and maintained on Gamborg's B5 medium until large enough for transfer into pots and culture under glasshouse conditions.

\section{Molecular marker assays}

AFLP analysis AFLP reactions were carried out substantially as described in Vos et al. (1995) using adapters, nonselective and selective primers obtained from Keygene Inc. Briefly, $2.5 \mu \mathrm{g}$ of genomic DNA were digested with $5 \mathrm{U} / \mu \mathrm{g}$ of EcoRI and MseI and ligated with EcoRI and MseI adapters. The biotin subtraction step was omitted and the ligated templates were preamplified with E00/M00 and E01/M01 primers. Parents and hybrid genotypes were selectively amplified with two primer pair combinations using the E00/M00 templates (E32M52, E34M43) and 16 primer pair combinations using the E01/M01 templates (E35M35, E35M31， E35M42， E35M38， E45M46, E36M35, E44M35, E44M45, E38M40, E44M46, E45M43, E40M41, E40M43, E40M44, E45M31 and E45M45). AFLP bands were resolved on $6 \%$ denaturing polyacrylamide gels and visualized using the Silver Sequence DNA Staining Reagents (Promega).

Isoenzyme analysis Isoenzyme analyses for Pgi-2 (phosphoglucoisomerase locus), Est- $a$ and Est-c (esterase loci) were carried out on young leaf tissue according to Taing Aung \& Evans (1987).

\section{Statistical analysis}

Associations between the presence or absence of individual molecular markers and observed paired arm (PA) frequency in the hybrid population were tested for significance using the Mann-Whitney $U$-test (GENSTAT 5 - Release 4.1). Recombination frequencies and LOD values were obtained using JoINMAP 2.0 (Stam, 1993).

\section{Cytological analysis}

Emerging inflorescences were fixed in Carnoy's solution (6:3:1; ethanol:chloroform:acetic acid) for at least $24 \mathrm{~h}$ and stored in $70 \%$ ethanol. Squash preparations of pollen mother cells (PMCs) were stained in acetocarmine before microscopic examination. Approximately 20 PMCs were scored for univalent, rod bivalent and ring bivalent chromosome associations at metaphase I of meiosis in each of $47 \mathrm{~L}$. perenne $\times L$. temulentum hybrids and recorded as PA/PMC - giving a total of 998 scored PMCs. Rod bivalents were scored as containing one PA and ring bivalents two PAs. No attempt was made to score more than one chiasma in a paired chromosome arm and only those PMCs where all 14 chromosomes could be scored were included in the analysis.

\section{Results}

\section{Genetic analysis}

One hundred and twenty segregating AFLP loci and three isozyme loci were scored on the 47 hybrid 
(a)

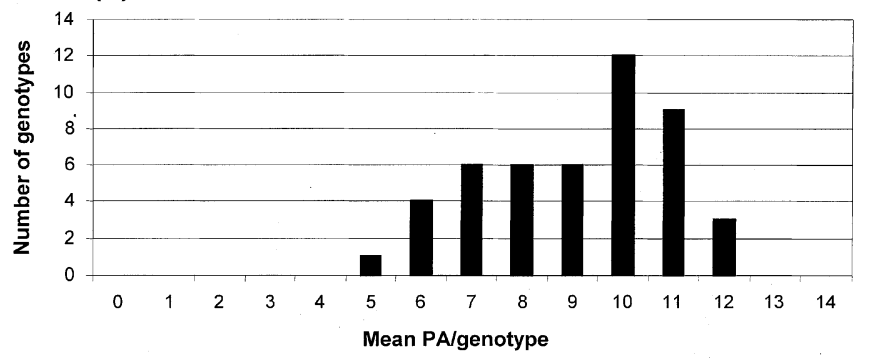

(b)

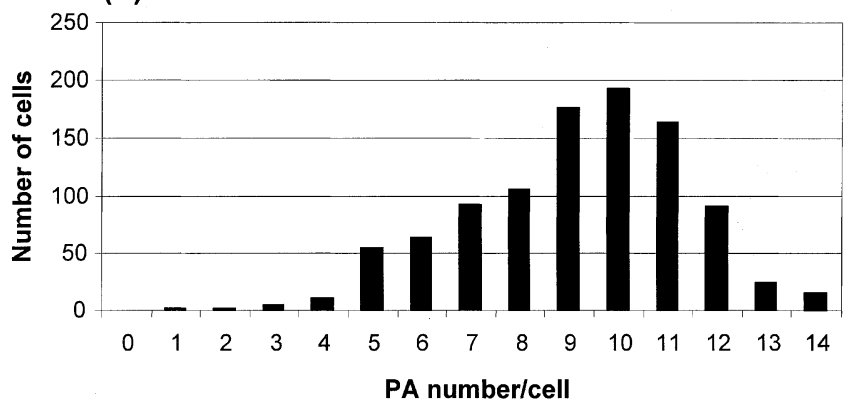

Fig. 1 (a) The mean paired arm (PA)/pollen mother cell (PMC)/genotype (nearest whole number) and (b) the PA/PMC at metaphase I of meiosis in Lolium perenne $\times$ L. temulentum hybrids. Individual PMCs were scored for univalents (0 PA), rod bivalents (1 PA) and ring bivalents (2 PA).

genotypes. The $U$-test indicated that two AFLP loci were significantly associated with higher or lower PA frequency with $P<0.01$ and a further eight AFLP loci with $P<0.05$. None of the isoenzyme loci was significantly associated with variation in PA frequency. In addition, the linkage of all the scored alleles to a hypothetical single gene influencing PA frequency and segregating $1: 1$ in the population (i.e. scored as being present in the 24 plants with the lowest PA frequencies and as being absent in the 23 plants with the highest PA frequencies) was assessed using JOINMAP. The closest linkage showed $30 \%$ recombination with the hypothetical gene, LOD 1.4.

\section{Cytological analysis}

The mean PA frequency was 9.1/cell (1.3 PA/chromosome pair) at meiosis in the hybrid population; the range of mean genotype values was between 5.25 and $11.8 \mathrm{PA} /$ cell (0.8-1.7 PA/chromosome pair) (Fig. 1a). This compares with frequencies of 13.4 and $12.6 /$ cell for L. temulentum Ba3018 and L. perenne Lp19, respectively (Jiménez \& Jenkins, 1995). The minimum number of PAs found was in one cell which had a single PA (i.e. one rod bivalent and 12 univalents) whereas 15 cells from 10 different genotypes had the maximum $14 \mathrm{PA} /$

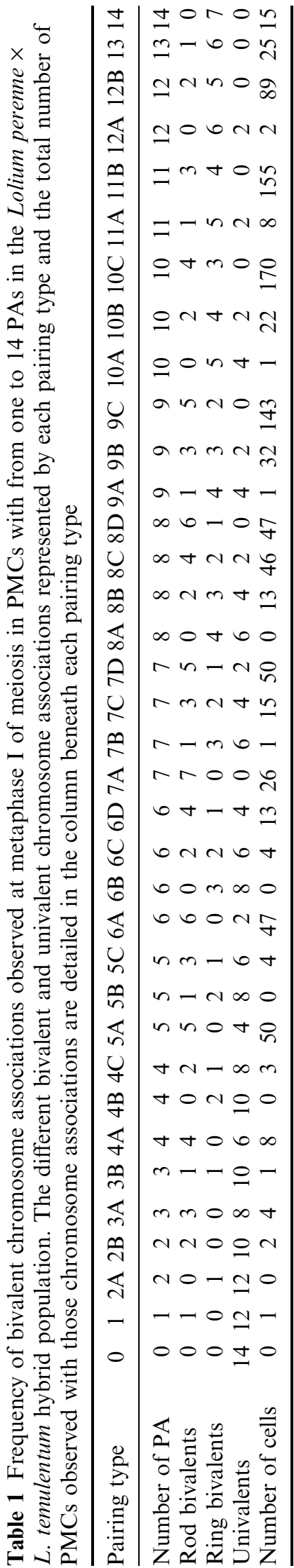

(c) The Genetical Society of Great Britain, Heredity, 83, 298-303. 
cell (i.e. 7 ring bivalents) (Fig. $1 \mathrm{~b}$ and Table 1). The mean bivalent frequency for the population was 6.4 bivalents/cell indicating that, on average, $>90 \%$ of the hybrid chromosomes formed homoeologous pairs at meiosis. The equivalent figures for Ba3081 and Lp19 were 6.98 and 7.00 , respectively, so that very few univalents would be expected in the parental material (Jiménez \& Jenkins, 1995). The range of mean genotype bivalent values in the hybrid population was between 4.3 and seven bivalent chromosome pairs/cell. The distribution of the different PA frequencies between genotypes and cells was skewed towards higher PA frequencies (see Fig. 1a,b). These cytological observations are broadly in line with those obtained by previous workers on this and similar genotypes (Taylor \& Evans, 1977; Taing Aung \& Evans, 1987; Scanlon, 1988; Wolstenholme, 1993).

Table 1 details the relationships between the observed PA frequencies in the 998 scored cells and the 36 possible different pairing types which might, theoretically, be observed within the constraints of scoring only univalents, rod and ring bivalents (i.e. there is only one bivalent pairing type for deriving each of $0,1,13$ or 14 $\mathrm{PA} /$ cell, two bivalent pairing types for deriving 2, 3, 11 or $12 \mathrm{PA} /$ cell, three types for deriving 4, 5, 9 and $10 \mathrm{PA} /$ cell and four types for deriving 7 and $8 \mathrm{PA} /$ cell). Some bivalent pairing types occurred far more frequently than others (Table 1), with $56 \%$ of the cells having one of the four types $10 \mathrm{C}, 11 \mathrm{~B}, 9 \mathrm{C}$ and $12 \mathrm{~B}$. Although the most numerous PA frequency was $10 /$ cell, of the 193 cells which had this PA frequency, $88 \%$ had only one of the three possible bivalent pairing types for $10 \mathrm{PA}$, notably, the pairing type with the highest bivalent frequency (10C). This trend for the pairing type which gave the maximum number of bivalents for a given number of PAs being the most numerous can be seen for all the pairing type classes except $7 \mathrm{PA} /$ cell, in which the bivalent pairing type of 5 rods +1 ring is twice as numerous as 7 rods. Figure 2 illustrates how PAs are distributed between chromosomes to ensure the maximum possible number of bivalents. With an increase in PAs/cell there is a rapid decline in the number of univalents and a commensurate rise in the number of rod bivalents. The frequency of ring bivalents remains essentially unchanged until there are $7 \mathrm{PAs} /$ cell, after which an increase in the number of ring bivalents is accompanied by a decrease in the number of rod bivalents.

\section{Discussion}

It has been suggested that in the Lp19 line (from which $\mathrm{E} 5 / 2 / 5 / 10$ was derived) there were one or two segregating genes which could have a significant effect on

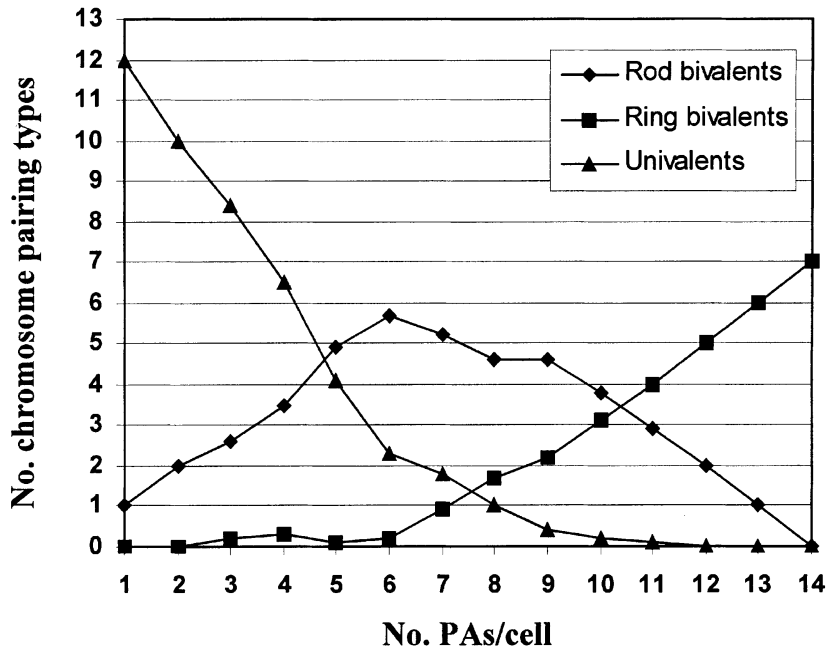

Fig. 2 The mean number of different chromosome pairing types in relation to the number of PAs/cell in the Lolium perenne $\times$ L. temulentum hybrid population.

chiasma frequency (Taing Aung \& Evans, 1987). They identified a statistically significant but distant $(R f$ value $=0.34$ ) linkage to the isoenzyme Est-c locus, though in two later analyses on related material, the results were more equivocal (Scanlon, 1988; Wolstenholme, 1993). However, all these studies were carried out before it was possible to undertake rapid genotyping using AFLP analysis and these earlier studies relied on the limited isoenzyme and RFLP assays that were then available for Lolium species.

Lolium temulentum Ba3081 is an inbred line and, thus, represents a homozygous background in which differential expression of alleles from E5/2/5/10 could be assessed. The relatively small population size and the possibility of there being progeny selection during embryo rescue and interspecific hybrid establishment mitigated against the desirability of undertaking comprehensive linkage analysis. However, if it is assumed that the 123 segregating alleles identified in this population were evenly distributed in the Lolium genome, then each chromosome would be expected to be sampled at $\approx 18$ different locations. Although this 'best-possible scenario' is unlikely to have occurred, the sampling should have been sufficient to 'tag' a gene of major effect. However, although there was a slight excess of statistically significant marker/trait associations over that which would be predicted by chance alone (of the 10 marker/trait associations with $P<0.05$, on average six would be attributable to chance alone and of the two marker/trait associations with $P<0.01$, on average at least one would be attributable to chance alone), the relatively high rates of recombination $(\geq 30 \%)$ observed between the significant alleles and the proposed single 
gene effect suggests that a more complex model will be required. So, although there are certainly genetic differences within and between Lolium populations which can influence chiasma frequency (Rees, 1974; Taylor \& Evans, 1977; Evans \& Davies, 1985; Evans \& Taing Aung, 1985; Taing Aung \& Evans, 1987), the present study indicates that the manipulation of recombination frequency in Lolium/Festuca is unlikely to be a simple process using the material currently available.

In both parental genotypes the formation of 12-14 PA/ cell would be expected. In the hybrid population the figure was $9.1 \mathrm{PA} /$ cell. The fact that there is a lower pairing efficiency (about a 30\% reduction as compared to the mean of the two parental types) in the interspecific hybrids is not surprising, particularly given the difference in chromosome length at meiosis and total DNA quantity that exists between the two species (Jenkins \& Scanlon, 1987). However, this $30 \%$ reduction in the number of PA was not reflected in an equivalent reduction in the number of bivalents formed; the reduction in this case was $<10 \%$. The lower PA frequency in the hybrid is attributable more to a decrease in the number of ring bivalents than to an increase in the number of univalents. Thus, as Fig. 3 illustrates, PAs were not randomly distributed in this population; there were $60 \%$ more rod bivalents, $21 \%$ fewer ring bivalents and $59 \%$ fewer univalents formed than would be expected if there were no bias against particular bivalent pairing types.

It is apparent that, in a number of species, the distribution of chiasmata within and between bivalents is not random; both the total chromosome length and chiasma interference and localization can influence the observed chiasma frequencies (reviewed by Jones, 1987). It is clear that L. perenne $\times L$. temulentum hybrids are no exception to this in that there seems to be a mechanism present that actively 'distributes' the number of PAs

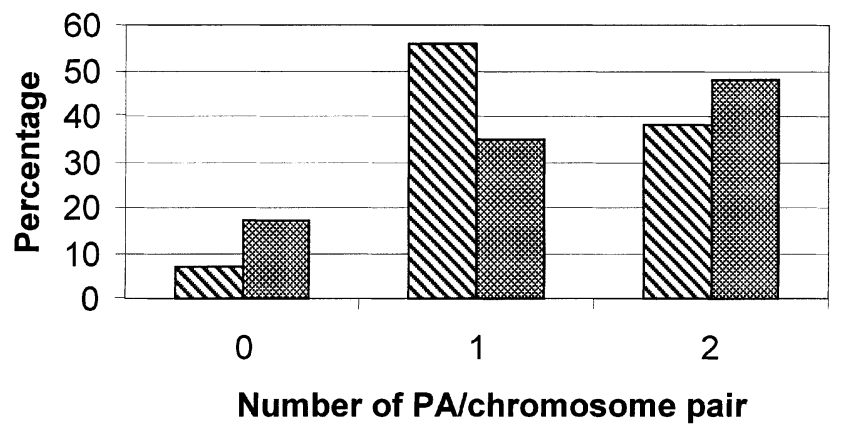

Fig. 3 The percentage frequency distribution of the number of $\mathrm{PA} /$ chromosome pair at metaphase I of meiosis in PMCs of the Lolium perenne $\times$ L. temulentum hybrid population. $\mathbb{\nabla}=$ the observed frequencies. $\square=$ the expected frequencies derived from the actual PA counts with no bias towards particular bivalent pairing types. between chromosomes so as to maximize the total number of bivalents formed. What the underlying control for this mechanism might be is not yet understood, but the mechanism is not disrupted by the reduced number of PAs in the lowest-pairing hybrid genotypes.

The identification of a major gene influencing chiasma frequency and distribution in forage grasses (similar to the $P h$ gene in wheat or comparable genetic systems in rye; Jones, 1967) would be of great value to forage grass breeders in terms of enabling them to exercise greater control over genome stability in diploid hybrids and, especially, in synthetic polyploid combinations. The work of Evans and colleagues had suggested that there may be a forage grass $P h$-type gene in E5/2/5/10 which might be active both at the diploid and the polyploid levels. This analysis uncovered no evidence for such a gene at the diploid level. E5/2/5/10 had been selected as a 'low-pairing' genotype but still showed high degrees of bivalent formation in a cross with the cytologically very different $L$. temulentum. Similar experiments with 'high-pairing' genotypes may help us to understand better the cytological and genetic basis of hybrid recombination in Lolium and thus to develop breeding lines which will improve the efficiency with which interspecific hybridization and introgression can be exploited.

\section{Acknowledgements}

The authors would like to thank Mr C. Evans (IGER), Dr M. O. Humphreys (IGER) and Mr D. Fallding (University Wales, Aberystwyth) for their expertise in isoenzyme analysis, statistical analysis and embryo rescue, respectively. This research was supported by the BBSRC through the Plant and Animal Genome Analysis Programme (PAG/04444).

\section{References}

EVANS, G. M. AND DAVIES, E. W. 1985. The genetics of meiotic chromosome pairing in Lolium temulentum $\times$ Lolium perenne tetraploids. Theor. Appl. Genet., 71, 185-192.

EVANS, G. M. AND TAING AUNG. 1985. Identification of a diploidizing genotype of Lolium multiflorum. Can. J. Genet. Cytol., 27, 498-505.

HUMPHREYS, M. W. AND PASAKINSKIENE, I. 1996. Chromosome painting to locate genes for drought resistance transferred from Festuca arundinacea into Lolium multiflorum. Heredity, 77, 530-534.

JENKINS, G. AND SCANLON, M. J. 1987. Chromosome pairing in a Lolium temulentum $\times$ Lolium perenne diploid hybrid with a low chiasma frequency. Theor. Appl. Genet., 73, 516-522.

JIMÉNEZ, G. AND JENKINS, G. 1995. Lateral element lengths and nuclear disposition in Lolium. Heredity, 75, 273-280.

JONES, G. H. 1967. The control of chiasma distribution in rye. Chromosoma, 22, 69-90.

(c) The Genetical Society of Great Britain, Heredity, 83, 298-303. 
JONES, G. H. 1987. Chiasmata. In: Moens, P. B. (ed.) Meiosis, pp. 213-244. Academic Press, London.

REES, H. AND DALE, P. J. 1974. Chiasmata and variability in Lolium and Festuca populations. Chromosoma, 47, 335-351. SCANLON, M. J. 1988. The Manipulation of Diploidizing Genes in Lolium. PhD Thesis, University College of Wales, Aberystwyth.

STAM, P. 1993. Construction of integrated genetic linkage maps by means of a new computer package: JoINMAP. Plant J., 3, 739-744.

TAING AUNG AND EVANS, G. M. 1985. The potential for diploidizing Lolium multiflorum $\times$ L. perenne tetraploids. Can. J. Genet. Cytol., 27, 506-509.

TAING AUNG AND EVANS, G. M. 1987. Segregation of isoenzyme markers and meiotic pairing control genes in Lolium. Heredity, 59, 129-134.
TAYLOR, I. B. AND EVANS, G. M. 1977. The genotypic control of homoeologous chromosome association in Lolium temulentum $\times$ Lolium perenne interspecific hybrids. Chromosoma, 62, 57-67.

THOMAS, H. M., MORGAN, W. G., MEREDITH, M. R., HUMPHREYS, M. W., THOMAS, H. AND LEGGETT, J. M. 1994. Identification of parental and recombined chromosomes in hybrid derivatives of Lolium multiflorum $\times$ Festuca pratensis by genomic in situ hybridization. Theor. Appl. Genet., 88, 909-913.

VOS, P., HOGERS, R., BLEEKER, M., REIJANS, M., VAN DE LEE, T., HORNES, M. ET AL. 1995. AFLP: a new technique for DNA fingerprinting. Nucl. Acids Res., 23, 4407-4414.

wOlSTENHOLMe, L. J. 1993. Genome Studies in Lolium and Festuca. $\mathrm{PhD}$ Thesis, University College of Wales, Aberystwyth. 